\title{
Faecal Inflammatory Biomarkers and Gastrointestinal Symptoms after Bariatric Surgery: A Longitudinal Study
}

\author{
Floris Westerink $^{a}$ Inge Huibregtse ${ }^{b}$ Marieke De Hoog ${ }^{c}$ Sjoerd Bruin $^{d}$ \\ Eelco Meesters ${ }^{\mathrm{e}}$ Desiderius Brandjes ${ }^{\mathrm{a}}$ Victor Gerdes ${ }^{\mathrm{a}} \mathrm{e}$ \\ aDepartment of internal medicine, Amsterdam University Medical Centre, Amsterdam, The Netherlands; \\ bepartment of gastroenterology, Netherlands Cancer Institute, Antoni van Leeuwenhoek, Amsterdam, The \\ Netherlands; ' $S$ paarne Gasthuis Academy, Hoofddorp, The Netherlands; ${ }^{d}$ Department of surgery, Spaarne Gasthuis, \\ Hoofddorp, The Netherlands; 'Department of internal medicine, Spaarne Gasthuis, Hoofddorp, The Netherlands
}

\section{Keywords}

Roux-en-Y gastric bypass - Bariatric surgery - Calprotectin · IBD . Faecal biomarker

\begin{abstract}
Background: Bariatric surgery induces various gastrointestinal (Gl) modifications. We performed the first study longitudinally assessing the effect of bariatric surgery on faecal inflammatory biomarker levels and its relation with Gl complaints. Method: Faecal calprotectin, lactoferrin, and calgranulin-C levels were determined in 41 patients (34 Roux-en-Y [RYGB], 7 sleeves) before and at 6-16 weeks, 6 months, and 1 year after surgery. Changes in biomarker levels and percentage of patients above reference value were determined. Gastrointestinal symptom rating scale (GSRS) was used to assess Gl complaints at corresponding time points. The postoperative relation between GSRS score and biomarker levels above reference value was investigated. Results: After RYGB, median calprotectin levels are significantly higher $(>188,104-415 \mu \mathrm{g} / \mathrm{g}$ ) than before surgery (40, $19-78 \mu \mathrm{g} / \mathrm{g} ; p<0.001)$, and over $90 \%$ of patients have levels above reference value 1 year after surgery. Median lactoferrin was $0.4(0.2-1.6) \mu \mathrm{g} / \mathrm{g}$ before, and $>5.9(1.8-13.6) \mu \mathrm{g} / \mathrm{g}$
\end{abstract}

karger@karger.com www.karger.com/iid

Karger!

GOPEN ACCESS
(C) 2021 The Author(s)

Published by S. Karger AG, Basel

This is an Open Access article licensed under the Creative Commons Attribution-NonCommercial-4.0 International License (CC BY-NC) (http://www.karger.com/Services/OpenAccessLicense), applicable to the online version of the article only. Usage and distribution for commercial purposes requires written permission. after surgery $(p<0.001)$. Median calgranulin-C levels remained far below the reference value and were $0.13(0.05-$ $0.24) \mu \mathrm{g} / \mathrm{g}$ before and $<0.23(0.06-0.33) \mu \mathrm{g} / \mathrm{g}$ after surgery. Similar results were found after sleeve gastrectomy. No difference was seen in GSRS score for patients with calprotectin and lactoferrin levels above reference values. Conclusion: Faecal inflammatory biomarkers calprotectin and lactoferrin, but not calgranulin-C, rise above reference values shortly after bariatric surgery and remain elevated in the majority of patients. The discrepancy between calprotectin and calgranulin-C levels suggests no Gl inflammation. Furthermore, patients after RYGB with biomarkers above the population reference value do not seem to have more Gl complaints.

(c) 2021 The Author(s)
Published by S. Karger AG, Basel

\section{Introduction}

Numerous gastrointestinal (GI) complaints such as upper abdominal pain are associated with increasing BMI and obesity [1]. Bariatric surgery, like Roux-en-Y gastric bypass (RYGB) and sleeve gastrectomy (SG), is an effective therapy for morbid obesity [2]. After bariatric surgery, some of these GI complaints may improve, though 
often complaints start after surgery or pre-existent symptoms aggravate [3-7]. Bariatric surgery induces multiple GI modifications which can, in search of the origin of postoperative GI complaints, be of importance. Gastric pouch $\mathrm{pH}$ increases, GI hormone levels change, bile acid levels, and composition as well as the gut microbiome are altered [8-10].

Gastrointestinal complaints after RYGB can be of various origins, occasionally serious and acute (e.g., internal herniation), often less severe and nutrition-related, caused by dumping syndrome or food intolerances. However, frequently no direct cause is found, complaints become chronic, and symptoms are attributed to irritable bowel syndrome (IBS) [11, 12]. The majority of patients have elevated levels of faecal calprotectin (fCP) several years after RYGB, which may indicate some degree of intestinal mucosal inflammation and may have implications for use of calprotectin as a diagnostic test after bariatric surgery $[13,14]$. The course of fCP after bariatric surgery has not been investigated yet.

Multiple faecal biomarkers are used in clinical practice to objectively measure intestinal inflammation, also after bariatric surgery. fCP is most frequently used for suspicion of inflammatory bowel disease (IBD). Other inflammatory faecal biomarkers are calgranulin-C (S100A12) and lactoferrin. All 3 are mainly released by activated neutrophilic granulocytes. Calprotectin and lactoferrin can also originate form monocytes, macrophages, lymphocytes, brush-border cells, and epithelium and therefore increase in noninflammatory conditions. Calgranulin- $\mathrm{C}$ is almost solely released by neutrophils and, therefore, more specific for inflammation [15]. Their release correlates with clinical disease activity scores [16-18] and tissue inflammation in IBD patients and is associated with leukocyte migration into the GI tract [19]. Whether this is also true for bariatric surgery patients remains to be determined. The aim of this prospective cohort study was to determine the levels and course of these different faecal biomarkers after bariatric surgery and to assess whether they are associated with GI complaints.

\section{Method}

The study was performed in a high volume bariatric surgery hospital in The Netherlands. Patients who fulfilled the criteria for bariatric surgery (BMI $\geq 40$ or $\geq 35 \mathrm{~kg} / \mathrm{m}^{2}$ with obesity-related comorbidities) were approached for participation in this study at the outpatient clinic. Exclusion criteria were systemic or chronic GI diseases that may affect faecal biomarkers and GI complaints, like IBD, GI malignancies, GI infections, previous radiotherapy, or bowel resections. Other exclusion criteria were diarrhoea at time of stool collection and NSAID usage with the inability to stop this at least 5 days prior to stool collection.

All patients had laparoscopic procedures. RYGB consisted of creating a $4 \times 8 \mathrm{~cm}$ gastric pouch, $50 \mathrm{~cm}$ biliary limb and $150 \mathrm{~cm}$ antecolic, and antegastric alimentary limb. With SG, a subtotal vertical gastrectomy was done along the lesser curvature, with preservation of the pylorus, leaving a tube-shaped remnant stomach of approximately $100 \mathrm{~mL}$.

\section{Data Collection}

Patient files were used to collect baseline characteristics like age, gender, weight, medication use, and comorbidities.

\section{Faeces Collection and Storage}

All patients were asked to collect faeces samples at home, 3 tubes at a time, using the faeces collection device $\mathrm{Fe}-\mathrm{Col}^{\circledR}{ }^{\circledR}$ (Greiner Bio-One, Kremsmünster, Austria). Specimens were delivered to the hospital within $48 \mathrm{~h}$ and stored at $-20^{\circ} \mathrm{C}$ until analysis. The first faeces samples were collected within $48 \mathrm{~h}$ prior to surgery.

\section{Laboratory Methods}

All samples were defrosted, homogenized, and analysed by the laboratory for clinical chemistry and haematology of the University Medical Centre Groningen. Calprotectin was analysed by ELISA after preparation (fCal, Bühlmann laboratories AG, Schönenbuch, Switzerland). Also, calgranulin-C and lactoferrin were analysed by ELISA according to manufacturer guidelines (F-INFL-EL-US, Cisbio Bioassays, Codolet, France and Lactoferrin Scan, TechLab Blacksburg, USA respectively). Results are presented in micrograms per gram faeces $(\mu \mathrm{g} / \mathrm{g})$.

\section{Gastrointestinal Complaints}

Patients were asked to complete the Gastrointestinal Symptom Rating Scale (GSRS) questionnaire on the same days of faeces collection. The GSRS is a validated questionnaire for GI complaints on which patients score 15 GI symptoms on a seven-point Likert scale $(0=$ no complaints, $6=$ maximal complaints, and total minimum-maximum score: $0-90$ points).

\section{Definition of Outcomes}

We were primarily interested in the level of the different faecal inflammatory biomarkers over time. Levels were determined before and 6-16 weeks, 6 months, and 1 year after bariatric surgery. Proportions of patients with levels above the reference value are determined. Reference values used in this study are identical to manufacturer reference values and cutoff values frequently used in clinical practise or literature. A calprotectin value of $>50 \mu \mathrm{g} / \mathrm{g}$, lactoferrin of $>7.3 \mu \mathrm{g} / \mathrm{g}$, and calgranulin-C of $>0.75 \mu \mathrm{g} / \mathrm{g}$ are considered abnormal. As calprotectin of $>200 \mu \mathrm{g} / \mathrm{g}$ is also used in clinical practise as a cutoff for additional diagnostics, this level was included in the analysis as well.

Secondary outcome variable was GI complaints, scored with the GSRS. We aimed to determine the associations with elevated biomarker levels in the bariatric surgery population, making the biomarkers now an exposure variable. Also, associations between elevated biomarker value and the 3 separate GSRS items abdominal pain, urge for defecation and diarrhoea were evaluated, as these symptoms are part of the clinical activity index scores, used for IBD. 
Table 1. Patients' characteristics

\begin{tabular}{lrr}
\hline & RYGB, & $\begin{array}{l}\text { Sleeve, } \\
n=34\end{array}$ \\
\hline Age in years at time of surgery, mean (SD) & $46.8(11.4)$ & $42.4(10.5)$ \\
Female sex, $n$ (\%) & $29(85.3)$ & $6(85.7)$ \\
Preoperative weight in kilograms, mean (SD) & $121.6(18.5)$ & $124.6(13.8)$ \\
Preoperative BMI, kg/m ${ }^{2}$, mean (SD) & $42.5(4.5)$ & $43.1(4.8)$ \\
Diabetes mellitus preoperative, $n(\%)$ & $8(23.5)$ & $0(0)$ \\
Hypertension preoperative, $n$ (\%) & $14(41.2)$ & $1(14.3)$ \\
\% Total body weight loss at time of last sample collection, mean (SD) & $32.3(8.0)$ & $33.2(6.1)$ \\
\hline
\end{tabular}

RYGB, Roux-en-Y, gastric bypass; $n$, number of patients; SD, standard deviation.

Statistical analysis: descriptive statistics are used to report values of the faecal biomarker calprotectin, calgranulin-C, and lactoferrin and GSRS score preoperative and for all postoperative time points. For each of the biomarkers, postoperative values are compared to preoperative values using the Wilcoxon signed-rank test for paired nonparametric distributed data. Correlations between the 3 biomarkers are determined with Spearman's rank order correlation for all time points as well as associations between values of the individual biomarkers.

Generalized estimating equations are used for the longitudinal analyses to determine whether there is an association between total GSRS score and patients with faecal biomarker levels above the reference values, corrected for BMI as patients with increasing body weight have more GI complaints and higher calprotectin values. Because of the small number of patients with a SG, for this group of patients only descriptive statistics are used.

For all analyses, $p<0.05$ was considered statistically significant. All statistical analyses were executed with SPSS package 25 (IBM, Armonk, NY, USA).

\section{Results}

A total of 41 patients were included in the study of which 34 patients had a RYGB. Seven patients had a SG. Patient characteristics are presented in Table 1.

Between 2016 and 2018, a total of 469 of the expected 492 (95\%) faeces samples were collected. One patient had samples missing at 2 time points due to lost of follow-up. For all other patients, samples were collected at least at 3 time points. Missing samples were because of patient inability to collect and deliver the samples to the hospital within the right time frame. One collected sample could not be analysed because of an insufficient amount of faeces.

A total of 155 (94.5\%) GSRS questionnaires were completed of which total scores were calculated. Seven (5 RYGB and 2 sleeves) patients had 1 questionnaire missing, 1 patient had 2 questionnaires missing (RYGB). The results described below are based on RYGB patients only.

\section{Biomarker Values}

Median calprotectin value was $40 \mu \mathrm{g} / \mathrm{g}$ before surgery and 290, 240, and $188 \mu \mathrm{g} / \mathrm{g}, 6-16$ weeks, 6 months, and 1 year after surgery respectively. All postoperative values significantly differed from the preoperative value $(p<$ 0.001 ). Median lactoferrin was $0.4 \mu \mathrm{g} / \mathrm{g}$ before surgery, $11.0 \mu \mathrm{g} / \mathrm{g} 6-16$ weeks after, $7.3 \mu \mathrm{g} / \mathrm{g} 6$ months after, and $5.9 \mu \mathrm{g} / \mathrm{g} 1$ year after surgery. Again all postoperative values significantly differed from preoperative $(p<0.001)$. Median calgranulin- $C$ levels remained far below the reference value and were 0.13 before surgery, $0.16,0.17$, and $0.23 \mu \mathrm{g} / \mathrm{g}$ after surgery respectively at the aforementioned time points. Figure 1 displays pre- and postoperative levels of the biomarkers and GSRS score. One year after RYGB, over $90 \%$ of patients had calprotectin values above reference value. Figure 2 shows percentage of patients above reference value for all separate biomarkers.

\section{Correlations of Biomarkers}

For calprotectin and lactoferrin, the preoperative values were not related to any of their postoperative values. After surgery, the calprotectin values did correlate $(r$ $0.38-0.46, p<0.05)$, as did lactoferrin values $(r 0.70-0.82$, $p<0.01)$. Calgranulin-C values correlated at all time points $(r 0.47-0.73, p<0.01)$.

When we evaluated correlations between biomarkers, a relation between calprotectin and lactoferrin was seen at all time points $(r 0.47-0.65, p<0.01)$. Lactoferrin and calgranulin-C correlated before surgery $(r 0.48, p<0.01)$ but not after surgery. There was no significant correlation between calprotectin and calgranulin-C. Also, no signifi- 


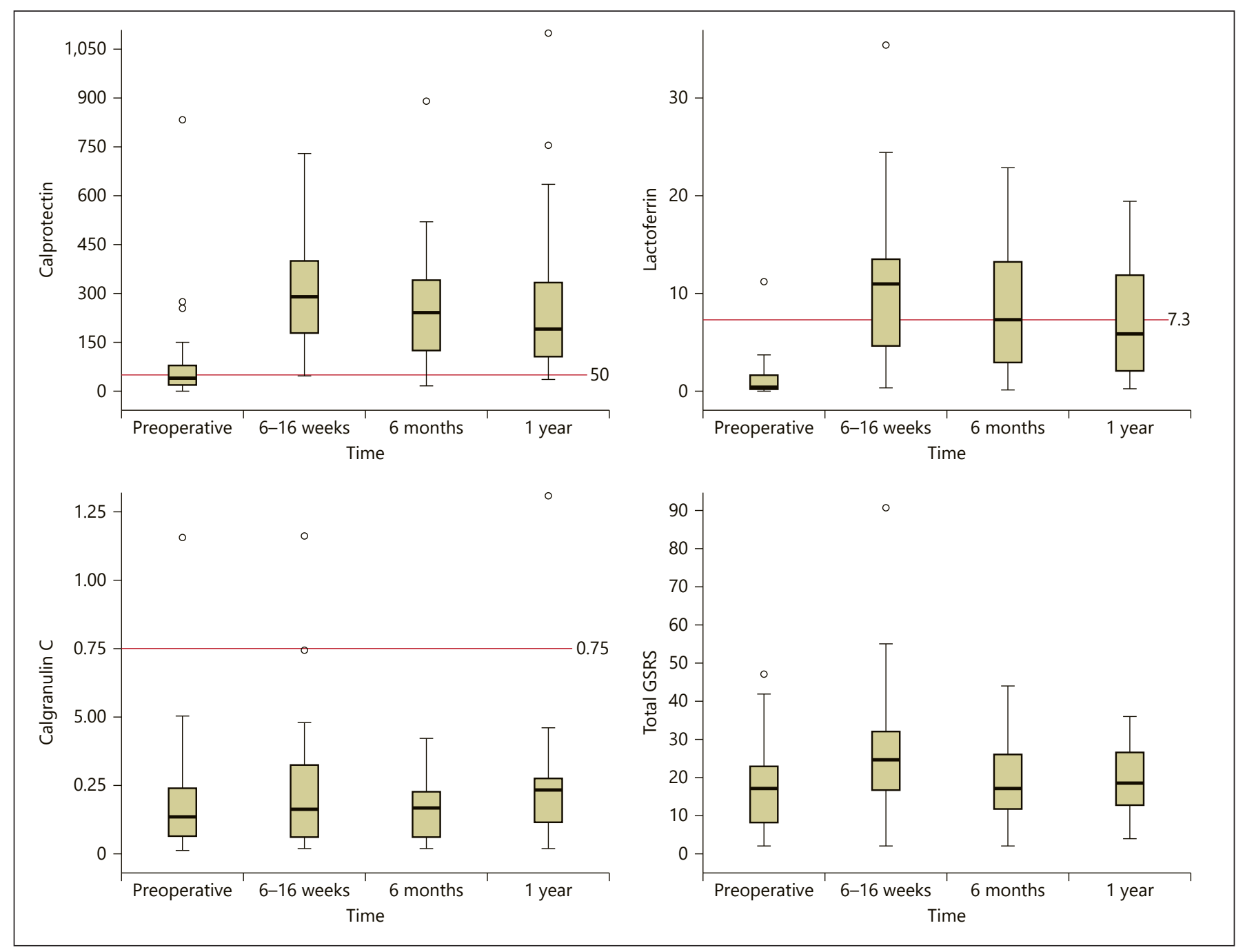

Fig. 1. Faecal biomarker values and total GSRS scores in RYGB patients. Boxplots depict the biomarkers in $\mu \mathrm{g} / \mathrm{g}$. Lines indicate reference values. Due to scale adjustment for readability 3 calgranulin-C outliers are not shown in figure: $2.03 \mu \mathrm{g} / \mathrm{g}$ preoperative, $3.77 \mu \mathrm{g} / \mathrm{g}$ at $6-16$ weeks, and $1.71 \mu \mathrm{g} / \mathrm{g}$ at 6 months.

cant correlation was found for biomarker values and BMI or \%total body weight loss before or after surgery.

\section{Associations Biomarkers and GSRS}

Patients mean GSRS scores are presented in Figure 1. Before surgery patients scored highest (median 2-2.5) on the items hunger and flatulence. After surgery, they had highest scores for borborygmi, belching, and flatulence (median 2-3).

The postoperative association between elevated biomarker levels and GSRS scores for RYGB patients is presented in Table 2. After adjusting for BMI, analysis showed no higher GSRS scores, on average, for patients with calprotectin values above $50 \mu \mathrm{g} / \mathrm{g}$ ( $\beta$ 2.53; 95\% CI: $-2.06-7.11)$ and lactoferrin values $>7.3 \mu \mathrm{g} / \mathrm{g}(\beta 4.79 ; 95 \%$ CI: -0.35-9.94) compared to patients with biomarker values below this reference value. Patients with calgranulinC levels above $0.75 \mu \mathrm{g} / \mathrm{g}$ scored lower on the GSRS ( $\beta$ -6.96 ; $95 \%$ CI: -12.60 to -1.32$)$, though few $(n=3)$ calgranulin-C samples were above the reference value. No difference was found for calprotectin values $>200 \mu \mathrm{g} / \mathrm{g}$ on GSRS score neither unadjusted nor adjusted for BMI.

When we evaluated GSRS items abdominal pain, urge for defecation, and diarrhoea separately, we observed no association with postoperative calprotectin levels above $50 \mu \mathrm{g} / \mathrm{g}$. Lactoferrin levels of $>7.3 \mu \mathrm{g} / \mathrm{g}$ were associated 
Fig. 2. Percentage of RYGB patients with faecal biomarker values above the reference value. Values in $\mu \mathrm{g} / \mathrm{g}$. For calprotectin, 2 reference values are depicted. fCP, faecal calprotectin.

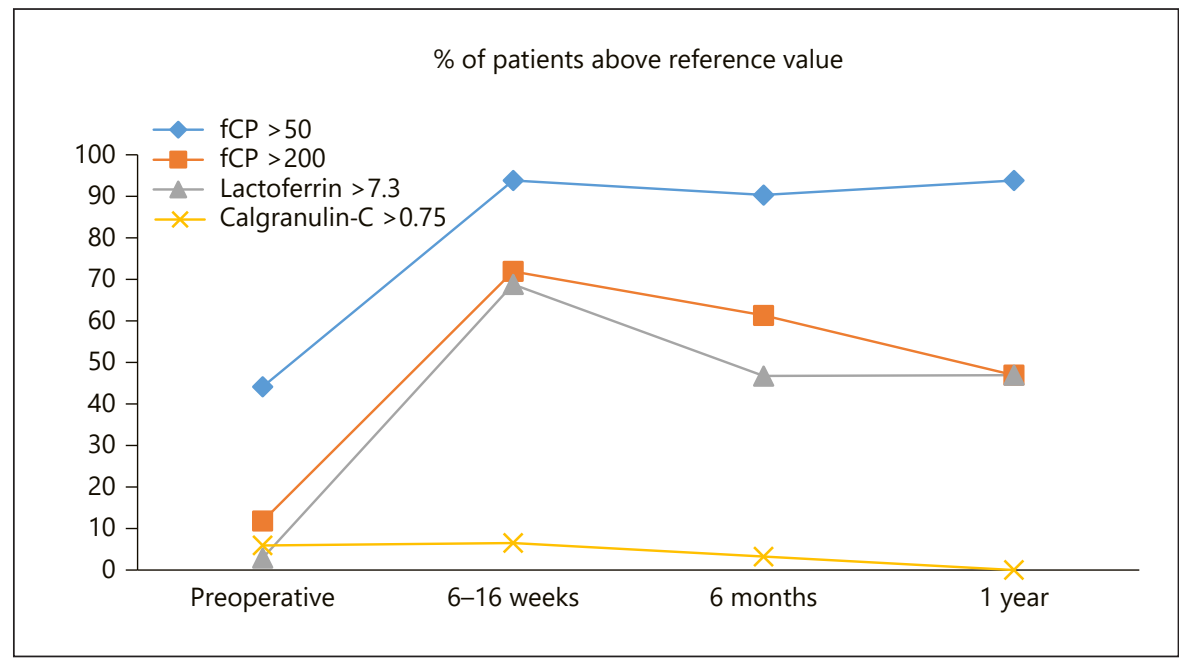

Table 2. Association GSRS score and biomarkers above reference value for RYGB patients

\begin{tabular}{lll}
\hline & $\begin{array}{l}\text { Unadjusted } \\
\beta(95 \% \mathrm{CI})\end{array}$ & $\begin{array}{l}\text { Adjusted for BMI } \\
\beta(95 \% \mathrm{CI})\end{array}$ \\
\hline Calprotectin $<50$ & Ref & Ref \\
Calprotectin $>50$ & $4.75(0.81-8.69)$ & $2.53(-2.06$ to 7.11$)$ \\
Calprotectin $<200$ & $\operatorname{Ref}$ & $\operatorname{Ref}$ \\
Calprotectin $>200$ & $0.78(-3.21-4.76)$ & $-0.83(-5.28$ to 3.61$)$ \\
Lactoferrin $<7.3$ & Ref & $\operatorname{Ref}$ \\
Lactoferrin $>7.3$ & $5.57(0.45-10.70)$ & $4.79(-0.35$ to 9.94$)$ \\
Calgranulin-C $<0.75$ & Ref & $\operatorname{Ref}$ \\
Calgranulin-C $>0.75$ & $-5.42(-8.14$ to -2.70$)$ & $-6.96(-12.60$ to -1.32$)$ \\
\hline
\end{tabular}

Biomarker reference values in $\mu \mathrm{g} / \mathrm{g}$.

with higher scores on urgent need for defecation $(\beta 0.62$, $95 \%$ CI $0.05-1.18, p<0.05$ ), but not abdominal pain or diarrhoea.

\section{Sleeve Gastrectomy Patients}

Biomarkers levels for SG patients and the GSRS scores are displayed in Table 3. No statistical analysis is performed because of small numbers of patients.

\section{Discussion}

This is the first study that longitudinally assessed faecal inflammatory biomarker changes before and after bariatric surgery. Almost all patients have increasing fCP levels, rising above the reference value shortly after bariatric surgery. Nearly half the patients have calprotectin levels above $200 \mu \mathrm{g} / \mathrm{g} 1$ year after RYGB. This is, to a lesser extent, also the case for SG patients. Also, faecal lactoferrin increases in the majority of patients after RYGB, showing a similar pattern as calprotectin. Approximately, half of the patients have lactoferrin levels above the reference value 1 year after RYGB. This change was not seen after SG where levels remained normal. Interestingly, unlike calprotectin and lactoferrin, faecal calgranulin-C levels do not change after bariatric surgery. No patients had values above the reference value 1 year after RYGB.

This is the first study that provides data on faecal lactoferrin and calgranulin- $\mathrm{C}$ levels after bariatric surgery. Two previous studies measured fCP levels, 1-2 years after RYGB, and described similar levels $[13,14]$. Both were cross-sectional studies, hence, unlike this study, preoperative data and the course of calprotectin values after surgery were not available. 
Table 3. Biomarker levels and total GSRS score for SG patients

\begin{tabular}{lclll}
\hline & $\begin{array}{l}\text { Calprotectin } \\
\text { median }(25-75 \text { perc.) }\end{array}$ & $\begin{array}{l}\text { Lactoferrin } \\
\text { median }(25-75 \text { perc. })\end{array}$ & $\begin{array}{l}\text { Calgranulin-C } \\
\text { median }(25-75 \text { perc. })\end{array}$ & $\begin{array}{l}\text { GSRS score } \\
\text { mean (SD) }\end{array}$ \\
\hline Preoperative & $55(46-1,290)$ & $1.8(0.3-12.0)$ & $0.17(0.04-0.22)$ & $12.6(9.2)$ \\
6-16 weeks po. & $403(190-587)$ & $3.4(2.3-8.9)$ & $0.22(0.04-0.45)$ & $17.4(11.4)$ \\
6 months po. & $76(33-301)$ & $1.1(0.0-5.0)$ & $0.10(0.05-0.18)$ & $21.6(16.3)$ \\
1 year po. & $157(55-170)$ & $1.8(0.2-2.6)$ & $0.17(0.09-0.23)$ & $18.0(8.8)$ \\
\hline
\end{tabular}

Biomarker values in $\mu \mathrm{g} / \mathrm{g}$. po., postoperative; perc., percentile; SD, standard deviation; SG, sleeve gastrectomy.

Calprotectin and lactoferrin mainly originate from neutrophilic cytoplasm and calgranulin- $\mathrm{C}$ are solely released by neutrophils $[20,21]$. This is why these biomarkers are associated and elevated in the faeces of patients with active IBD. As calgranulin-C levels remain normal after bariatric surgery, there seems to be no postoperative GI mucosal inflammation with neutrophilic involvement, and a different source for the increased calprotectin and lactoferrin levels is probable.

Possibly, other (known) mechanisms that elevate fCP are put in motion by RYGB. Calprotectin can to a lesser extent be found in other cell types than neutrophils and levels can change for multiple reasons. Several GI abnormalities can increase calprotectin like (anastomotic) ulcers, neoplasia's, bacterial and viral infections, clostridium difficile [22, 23], exocrine pancreas insufficiency [24, 25], and nonsteroidal anti-inflammatory drugs [26]. Moreover, mucosal barrier defects can increase gut permeability and the influx of granulocytes into the GI lumen due to large numbers of GI bacteria [27]. Even transmucosal leakage of calprotectin into the GI lumen has been described $[28,29]$. Furthermore, lifestyle and diet alterations [30], specific age-related changes in inflammatory cells in the GI mucosa [31] and changes in both cellular and humoral immunity [32] can influence calprotectin and lactoferrin levels. Possibly, RYGB induces 1 or more of the aforementioned processes. Future research is needed to determine the effect of several postbariatric GI changes, like microbiome and bile acid alterations, on biomarker values.

It is known that the majority of patients experience an increase in GI complaints after RYGB, the reason for this is often not well known. In this study, after RYGB, calprotectin and lactoferrin levels above the population reference values were not associated with higher GI symptom scores, after adjusting for BMI. Unadjusted, only minor differences were seen. Higher faecal calgranulin-C levels were associated with less severe GI symptoms, but nearly all patients had normal calgranulin-C levels, before and after surgery.

No prior studies have been published in which the association between GI complaints and faecal inflammatory biomarkers was assessed in the bariatric surgery population. In IBD patients, symptom severity and clinical assessment of disease activity are associated with faecal biomarker levels [33-35]. Clinicians should be aware of an altered relation between GI complaints and fCP after bariatric surgery, probably due to a different origin of the biomarkers and GI complaints.

Interestingly, also patients with calprotectin values of $>200 \mu \mathrm{g} / \mathrm{g}$ did not have more GI complaints than patients with lower calprotectin levels. With almost half of the patients after RYGB having calprotectin levels of $>200 \mu \mathrm{g} / \mathrm{g}$ and lactoferrin levels of $>7.3 \mu \mathrm{g} / \mathrm{g}$, and taking into account that GI complaints increase in the majority of patients after RYGB, the chance of performing (unnecessary) additional diagnostics like endoscopy in this population will be increased if population cutoff values are used. The median fCP level in the healthy population ranges from 9.3 to $31 \mu \mathrm{g} / \mathrm{g}$ [36]. No consensus on calprotectin cutoff values in the normal population exists, but a cutoff value of 50 $\mu \mathrm{g} / \mathrm{g}$ can distinguish between IBD and IBS with a sensitivity of $95 \%$ and specificity of $91 \%$ [37], with comparable accuracy for lactoferrin [38]. Values of $>200 \mu \mathrm{g} / \mathrm{g}$ are also used in daily practice, as a cutoff for additional diagnostics like endoscopy. In IBD, a system of multiple cutoff values has been proposed to differentiate between disease (in) activity $(>425 \mu \mathrm{g} / \mathrm{g})$, mucosal healing $(<158 \mu \mathrm{g} / \mathrm{g})$, and discriminate between IBS and IBD $(<188 \mu \mathrm{g} / \mathrm{g})$ [39]. It seems to be necessary to determine specific RYGB reference values for fCP and lactoferrin if the postoperative elevation is not due to inflammation but, for example, due to altered clearance of the protein. Simply raising calprotectin cutoff to $200 \mu \mathrm{g} / \mathrm{g}$ does not seem to be sufficient. Perhaps calgranulin- $\mathrm{C}$ is more reliable after bariatric surgery, however, we cannot substantiate this with our findings. 


\section{Study Limitations}

With the study design used, we are limited in determining the origin of GI calprotectin and lactoferrin. Endoscopy imaging and mucosal biopsies are needed, at least, to help determine if reference values can be adjusted and the role that is reserved for calgranulin-C in this population. They can also give more insight into the origin of the biomarkers. Future studies should focus on this.

Several procedural choices may have influenced biomarker values, though we believe effects are small. Single stool specimens were used, as this is less burdensome for patients to collect and there appears to be little difference with 4 days collected stool specimens [40]. All biomarkers are believed to be stable for at least $48 \mathrm{~h}$ at room temperature [41] and up to a year at $-20^{\circ} \mathrm{C}$. Some samples were stored for more than a year, which could have led to an underestimation of the values, though longer stored samples did not show lower levels than shorter stored faeces samples for all biomarkers at all time points. Furthermore, proton pump inhibitors (PPIs) are prescribed to all patients after bariatric surgery for 3 months in our hospital. It is reported that the use of a PPI might influence fCP levels $[42,43]$. In our previous study [13], no difference in calprotectin levels was found in PPI users and nonusers, so patients in this study were allowed to use PPIs. Relatively high levels of preoperative calprotectin were found, it is reported that higher calprotectin levels are found in patients with morbid obesity compared to the healthy population [44].

This study was not powered to detect changes in GI complaints before and after surgery. Therefore, changes in GSRS scores at the different time points were not analysed. This was done in a separate study [45].

Due to the small number of patients with a SG in this study, differences between both interventions could not be determined. Further research is needed to define the effect of SG on GI complaints and faecal biomarkers.

\section{Conclusions}

This study shows that the faecal inflammatory biomarkers calprotectin and lactoferrin, but not calgranulinC, rise above reference values shortly after bariatric surgery and remain elevated in the majority of patients. The discrepancy between calprotectin and calgranulin-C levels suggests no GI inflammation. Patients after RYGB with calprotectin and lactoferrin levels above the population reference values do not seem to have more GI complaints when adjusting for BMI. To prevent unnecessary invasive diagnostics like endoscopies due to false-positive faecal biomarker tests, it is important that clinicians are acquainted with these findings. Further research on the effect of separate GI alterations after bariatric surgery on inflammatory biomarker levels is needed to define origin and adjusted reference values.

\section{Statement of Ethics}

The medical Ethics Committee of the MC Slotervaart/Reade in Amsterdam judged and approved (January 13, 2016) this study (registration number NL55820.048.15). This study was performed in accordance with the ethical standards of the Helsinki Declaration. All patients provided written informed consent. Data were encrypted before storage and analysis.

\section{Conflict of Interest Statement}

There are no conflicts of interest.

\section{Funding Sources}

Foundation of Clinical Scientific Research Slotervaart hospital funded this study.

\section{Author Contributions}

In line with the ICMJE recommendations, all the authors substantially contributed to the conception or design of the work or the analysis and interpretation of the data, including drafting the work or revising it. All the authors gave final approval of this version of the paper and agreed to be accountable for all aspects of their work.

\section{References}

1 Eslick GD. Gastrointestinal symptoms and obesity: a meta-analysis. Obes Rev. 2012; 13(5):469-79.

2 Welbourn R, Pournaras DJ, Dixon J, Higa K, Kinsman R, Ottosson J, et al. Bariatric surgery worldwide: baseline demographic description and one-year outcomes from the second IFSO global registry report 2013-2015. Obes Surg. 2018;28(2):313-22.

3 Hogestol IK, Chahal-Kummen M, Eribe I, Brunborg C, Stubhaug A, Hewitt S, et al. Chronic abdominal pain and symptoms 5 years after gastric bypass for morbid obesity. Obes Surg. 2017;27(6):1438-45.

4 Gribsholt SB, Pedersen AM, Svensson E, Thomsen RW, Richelsen B. Prevalence of self-reported symptoms after gastric bypass surgery for obesity. JAMA Surg. 2016;151(6): 504-11. 
5 Ballem N, Yellumahanthi K, Wolfe M, Wesley MM, Clements RH. Gastrointestinal symptom improvement after Roux-en-Y gastric bypass: long-term analysis. Surg Obes Relat Dis. 2009 Sep-Oct;5(5):553-8.

6 Clements RH, Gonzalez QH, Foster A, Richards WO, McDowell J, Bondora A, et al. Gastrointestinal symptoms are more intense in morbidly obese patients and are improved with laparoscopic Roux-en-Y gastric bypass. Obes Surg. 2003;13(4):610-4.

7 Boerlage TC, van de Laar AW, Westerlaken S, Gerdes VE, Brandjes DP. Gastrointestinal symptoms and food intolerance 2 years after laparoscopic Roux-en-Y gastric bypass for morbid obesity. Br J Surg. 2017;104(4):393-400.

8 Nemati R, Lu J, Dokpuang D, Booth M, Plank LD, Murphy R. Increased bile acids and FGF19 after sleeve gastrectomy and Roux-en- $Y$ gastric bypass correlate with improvement in type 2 diabetes in a randomized trial. Obes Surg. 2018; 28(9):2672-86.

9 Aron-Wisnewsky J, Prifti E, Belda E, Ichou F, Kayser BD, Dao MC, et al. Major microbiota dysbiosis in severe obesity: fate after bariatric surgery. Gut. 2019;68(1):70-82.

10 Palleja A, Kashani A, Allin KH, Nielsen T, Zhang C, Li Y, et al. Roux-en-Y gastric bypass surgery of morbidly obese patients induces swift and persistent changes of the individual gut microbiota. Genome Med. 2016;8(1):67.

11 Blom-Hogestol IK, Aasbrenn M, Chahal-Kummen M, Brunborg C, Eribe I, Kristinsson J, et al. Irritable bowel syndrome-like symptoms and health related quality of life two years after Rouxen-Y gastric bypass: a prospective cohort study. BMC Gastroenterol. 2019;19(1):204.

12 Blom-Hogestol IK, Stubhaug A, Kristinsson JA, Mala T. Diagnosis and treatment of chronic abdominal pain 5 years after Roux-en-Y gastric bypass. Surg Obes Relat Dis. 2018 Oct;14(10): 1544-51.

13 Boerlage TC, Westerink F, Poland DC, Huibregtse IL, Acherman YI, Gerdes VE. Fecal calprotectin, elastase, and alpha-1-antitrypsin levels after Roux-en-Y gastric bypass; calprotectin is significantly elevated in the majority of patients. Obes Surg. 2016 Dec 1;26(12):2974-80.

14 Carswell KA, Vincent RP, Belgaumkar AP, Sherwood RA, Amiel SA, Patel AG, et al. The effect of bariatric surgery on intestinal absorption and transit time. Obes Surg. 2014;24(5):796-805.

15 Foell D, Wittkowski H, Roth J. Monitoring disease activity by stool analyses: from occult blood to molecular markers of intestinal inflammation and damage. Gut. 2009;58(6):859-68.

16 Langhorst J, Elsenbruch S, Mueller T, Rueffer A, Spahn G, Michalsen A, et al. Comparison of 4 neutrophil-derived proteins in feces as indicators of disease activity in ulcerative colitis. Inflamm Bowel Dis. 2005;11(12):1085-91.

17 Sugi K, Saitoh O, Hirata I, Katsu K. Fecal lactoferrin as a marker for disease activity in inflammatory bowel disease: comparison with other neutrophil-derived proteins. Am J Gastroenterol. 1996;91(5):927-34.

18 de Jong NS, Leach ST, Day AS. Fecal S100A12: a novel noninvasive marker in children with Crohn's disease. Inflamm Bowel Dis. 2006;12(7): 566-72.

19 Guerrant RL, Araujo V, Soares E, Kotloff K, Lima AA, Cooper WH, et al. Measurement of fecal lactoferrin as a marker of fecal leukocytes. J Clin Microbiol. 1992;30(5):1238-42.

20 Kaiser T, Langhorst J, Wittkowski H, Becker K, Friedrich AW, Rueffer A, et al. Faecal S100A12 as a non-invasive marker distinguishing inflammatory bowel disease from irritable bowel syndrome. Gut. 2007;56(12):1706-13.

21 Whitehead SJ, Ford C, Gama RM, Ali A, McKaig B, Waldron JL, et al. Effect of faecal calprotectin assay variability on the management of inflammatory bowel disease and potential role of faecal S100A12. J Clin Pathol. 2017;70(12):1049-56.

22 Barbut F, Gouot C, Lapidus N, Suzon L, SyedZaidi R, Lalande V, et al. Faecal lactoferrin and calprotectin in patients with Clostridium difficile infection: a case-control study. Eur J Clin Microbiol Infect Dis. 2017;36(12):2423-30.

23 Swale A, Miyajima F, Roberts P, Hall A, Little M, Beadsworth MB, et al. Calprotectin and lactoferrin faecal levels in patients with Clostridium difficile infection (CDI): a prospective cohort study. PloS one. 2014;9(8):e106118.

24 Dumoulin EN, Van Biervliet S, Langlois MR, Delanghe JR. Proteolysis is a confounding factor in the interpretation of faecal calprotectin. Clin Chem Lab Med. 2015;53(1):65-71.

25 Ellemunter H, Engelhardt A, Schüller K, Steinkamp G. Fecal calprotectin in cystic fibrosis and its relation to disease parameters: a longitudinal analysis for 12 years. J Pediatr Gastroenterol Nutr. 2017;65(4):438-42.

26 Tibble JA, Sigthorsson G, Foster R, Scott D, Fagerhol MK, Roseth A, et al. High prevalence of NSAID enteropathy as shown by a simple faecal test. Gut. 1999;45(3):362-6

27 Fagerhol MK. Calprotectin, a faecal marker of organic gastrointestinal abnormality. Lancet. 2000;356(9244):1783-4.

28 Walker WA. Gastrointestinal host defence: importance of gut closure in control of macromolecular transport. Ciba Found Symp. 1979(70): 201-19.

29 Davidson F, Lock RJ. Paediatric reference ranges for faecal calprotectin: a UK study. Ann Clin Biochem. 2017;54(2):214-8.

30 Poullis A, Foster R, Shetty A, Fagerhol MK, Mendall MA. Bowel inflammation as measured by fecal calprotectin: a link between lifestyle factors and colorectal cancer risk. Cancer Epidemiol Biomarkers Prev. 2004;13(2):279-84.

31 Dunlop SP, Jenkins D, Spiller RC. Age-related decline in rectal mucosal lymphocytes and mast cells. Eur J Gastroenterol Hepatol. 2004;16(10): 1011-5.

32 Burns EA, Leventhal EA. Aging, immunity, and cancer. Cancer Control. 2000;7(6):513-22.
33 Hyams JS, Ferry GD, Mandel FS, Gryboski JD, Kibort PM, Kirschner BS, et al. Development and validation of a pediatric Crohn's disease activity index. J Pediatr Gastroenterol Nutr. 1991; 12(4):439-47.

34 Puolanne AM, Kolho KL, Alfthan H, Ristimäki A, Mustonen H, Färkkilä M. Rapid fecal calprotectin test and symptom index in monitoring the disease activity in colonic inflammatory bowel disease. Dig Dis Sci. 2017;62(11):3123-30.

35 Dabritz J, Langhorst J, Lugering A, Heidemann J, Mohr M, Wittkowski H, et al. Improving relapse prediction in inflammatory bowel disease by neutrophil-derived S100A12. Inflamm Bowel Dis. 2013;19(6):1130-8.

36 Konikoff MR, Denson LA. Role of fecal calprotectin as a biomarker of intestinal inflammation in inflammatory bowel disease. Inflamm Bowel Dis. 2006;12(6):524-34.

37 von Roon AC, Karamountzos L, Purkayastha S, Reese GE, Darzi AW, Teare JP, et al. Diagnostic precision of fecal calprotectin for inflammatory bowel disease and colorectal malignancy. Am J Gastroenterol. 2007;102(4):803-13.

38 Schroder O, Naumann M, Shastri Y, Povse N, Stein J. Prospective evaluation of faecal neutrophil-derived proteins in identifying intestinal inflammation: combination of parameters does not improve diagnostic accuracy of calprotectin. Aliment Pharmacol Ther. 2007;26(7):1035-42.

39 Jha AK, Chaudhary M, Dayal VM, Kumar A, Jha SK, Jha P, et al. Optimal cut-off value of fecal calprotectin for the evaluation of ulcerative colitis: an unsolved issue? JGH Open. 2018;2(5):20713.

40 Roseth AG, Fagerhol MK, Aadland E, Schjonsby $\mathrm{H}$. Assessment of the neutrophil dominating protein calprotectin in feces. A methodologic study. Scand J Gastroenterol. 1992;27(9):793-8.

41 Lasson A, Stotzer PO, Öhman L, Isaksson S, Sapnara $\mathrm{M}$, Strid $\mathrm{H}$. The intra-individual variability of faecal calprotectin: a prospective study in patients with active ulcerative colitis. J Crohns Colitis. 2015;9(1):26-32.

42 Poullis A, Foster R, Mendall MA, Shreeve D, Wiener K. Proton pump inhibitors are associated with elevation of faecal calprotectin and may affect specificity. Eur J Gastroenterol Hepatol. 2003 May;15(5):573-4; author reply 574.

43 Lundgren D, Eklöf V, Palmqvist R, Hultdin J, Karling P. Proton pump inhibitor use is associated with elevated faecal calprotectin levels. A cross-sectional study on subjects referred for colonoscopy. Scand J Gastroenterol. 2019;54(2): 152-7.

44 Kant P, Fazakerley R, Hull MA. Faecal calprotectin levels before and after weight loss in obese and overweight subjects. Int J Obes. 2013;37(2): 317-9.

45 Boerlage TCC, Westerink F, van de Laar A, Hutten BA, Brandjes DPM, Gerdes VEA. Gastrointestinal symptoms before and after laparoscopic Roux-en-Y gastric bypass: a longitudinal assessment. Surg Obes Relat Dis. 2019 Jun;15(6):871-7. 